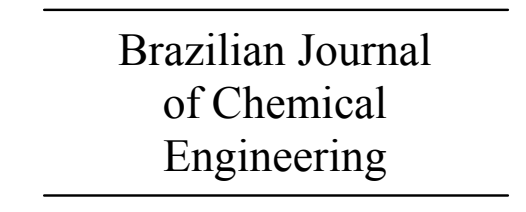

ISSN 0104-6632

Printed in Brazil

www.abeq.org.br/bjche

Vol. 30, No. 03, pp. 677 - 682, July - September, 2013

\title{
INFLUENCE OF POLYVINYLPYRROLIDONE ON THE INTERACTION BETWEEN WATER AND METHANOL
}

\author{
M. Guettari ${ }^{1 *}$ and R. Gomati ${ }^{2}$ \\ ${ }^{1}$ Unité de Recherche «NMR des Polymères et des Composites», Institut Préparatoire aux \\ Etudes d'Ingénieurs de Tunis, Montfleury Tunis, Université de Tunis, Tunisie. \\ ${ }^{2}$ Faculty of Science, Al Jouf-University, Kingdom of Saudi Arabia. \\ E-mail: gtarimoez@Yahoo.fr
}

(Submitted: October 25, 2011 ; Revised:July 17, 2012 ; Accepted: July 31, 2012)

\begin{abstract}
The present work aims to determine the influence of a dissolved polymer, polyvinylpyrrolidone, on the interaction between water and methanol. First, the dynamic viscosities were measured for polymer solutions by a rotational concentric cylinder at $25{ }^{\circ} \mathrm{C}$ and for the polymer concentration range from 0.1 to $0.6 \mathrm{~g} / \mathrm{dl}$. The results show a polynomial dependence of the viscosity on polymer concentration. On the hypothesis of a quasi-binary system, a pseudo Grumberg-Nissan constant, $d_{p}^{\prime}$, was introduced to quantify the interaction between unlike molecules in the presence of polymer. The interaction between unlike molecules due to the presence of the polymer was quantified by the deviation of the Grumberg-Nissan constant, $\delta d_{p}^{\prime}=d_{p}^{\prime}-d_{p}$. Generally, this constant is negative which means that the interactions between water and methanol decrease in the presence of polyvinylpyrrolidone at $25^{\circ} \mathrm{C}$. The presence of the polymer induces a perturbation of the dynamic equilibrium between free and complexed molecules.

Keywords: Viscosity; Rheology; Polymer; Mixed solvents; Interaction.
\end{abstract}

\section{INTRODUCTION}

It is well established that the mixture of water and an amphiphilic molecule provides a network due to the hydrogen bonds (Laaksonen et al., 1997; Wakisaka et al., 1998; Guo et al., 2003; Dixit et al., 2002; Dougan et al., 2004; Georgiev et al., 2007). In fact, experimental studies supported by computational investigations have been used to study the microscopic structure of this type of system, where clusters are formed between like and/or unlike molecules (Mikhail and Kimel, 1961; Zhao and Malinowski, 1999; Yilmaz, 2002; Gonzalez-Salgado and Nezbeda, 2006). In this type of system, the interaction between unlike molecules can be quantified from viscosity measurements and by calculating the Grumberg-Nissan constant d' (Grumberg and
Nissan, 1949). In our previous work (Guettari and Gharbi, 2011), a correspondence between the Grumberg-Nissan constant d' variation and the complexation in water/methanol mixtures was established. This result was extended to the mixture of water/ amphiphilic molecule.

Several studies have investigated the effect of the addition of an impurity, ionic or non-ionic, to a binary liquid mixture. These works were interested in the effect of an added impurity on the viscosity (Oleinikova et al., 1997; Huque et al., 2006; Zhao et al., 2006; Wang et al., 2004; Haldar and Das, 2008), conductivity (El. Dossoki, 2010), molar volume (Zhao et al., 2006), and density (Huque et al., 2006) of the binary liquid mixture. However, the effect on the microscopic structure of the binary liquid mixture was not taken into account, and only

*To whom correspondence should be addressed 
phenomenological interpretations were reported. In this study, we quantify the effect of the addition of a small quantity of a polymer, polyvinylpyrrolidone (PVP), on the microscopic structure of water/ methanol mixtures at $25^{\circ} \mathrm{C}$ and over a large range of mixture composition. The polymer used has been the subject of our previous investigations (Guettari et al., 2008; Guettari et al., 2010; Guettari and Gharbi, 2010), and this work is an extension of our earlier investigation (Guettari and Gharbi, 2011) concerning the microscopic structure of water/amphiphilic molecule mixtures by studying the interaction between unlike molecules. When the polymer concentration is small, the mixture can be considered as quasi-binary; thus, the mixture composition is assumed to be unchanged after polymer addition. Taking into account the last hypothesis, the deviation of the GrumbergNissan constant $\delta \mathrm{d}_{\mathrm{p}}^{\prime}$ due to the presence of the polymer was calculated as described in the theoretical background section.

First, the viscosities of polymer solutions were measured with a rotating co-axial cylinder. Then, the effects of the presence of the polymer on the microscopic structure of water/methanol mixtures were quantified and discussed according the deviation of the Grumberg-Nissan constant values.

\section{THEORETICAL BACKGROUND}

Competing forces include excluded-volume interactions, van der Waals interaction, and the solventmediated hydrodynamic interaction. According to Grumberg-Nissan (Grumberg and Nissan, 1949), the interaction between unlike molecules 1 and 2 can be quantified by calculating the constant $\mathrm{d}^{\prime}$ at a mole fraction of liquid $1, \mathrm{X}_{1}$, according to the following equation:

$$
\begin{aligned}
& \ln \left(\eta_{\mathrm{m}}\right)-\left[\mathrm{X}_{1} \ln \left(\eta_{1}\right)+\left(1-\mathrm{X}_{1}\right) \ln \left(\eta_{2}\right)\right], \\
& =X_{1}\left(1-\mathrm{X}_{1}\right) \mathrm{d}^{\prime}
\end{aligned}
$$

where $\eta_{1}, \eta_{2}$ and $\eta_{m}$ are respectively the dynamic viscosity of liquids 1,2 and the mixture. When a polymer is dissolved in a solvent $\mathrm{i}=(1,2)$ at low concentration $C$, the viscosity of solution $\eta_{i}^{*}$ can be approximated by the following equation (Couarraze and Grossiord, 2000):

$$
\eta_{i}^{*}=\eta_{i, 0}\left(1+a_{1, i} C+a_{2, i} C^{2}+a_{3, i} C^{3}+\ldots\right),
$$

where $\mathrm{a}_{1, \mathrm{i}}, \mathrm{a}_{2, \mathrm{i}}$ and $\mathrm{a}_{3, \mathrm{i}}$ are deduced from the viscosity data adjustment. $\eta_{i, 0}$ is the viscosity of liquid $i$ at zero polymer concentration.

When the liquids are mixed, the viscosity of the polymer solution $\eta_{\mathrm{m}}^{*}$ can be also expressed at low concentration by the following equation:

$$
\eta_{m}^{*}=\eta_{m, 0}\left(1+a_{1, m} C+a_{2, m} C^{2}+a_{3, m} C^{3}+\ldots\right),
$$

where $\mathrm{a}_{1, \mathrm{~m}}, \mathrm{a}_{2, \mathrm{~m}}$ and $\mathrm{a}_{3, \mathrm{~m}}$ are deduced from the viscosity data adjustment. $\eta_{\mathrm{m}, 0}$ is the viscosity of the mixed liquid at zero polymer concentration.

By assuming that the presence of polymer does not affect the composition of the binary mixture, we can define a pseudo Grumberg-Nissan constant $d_{p}^{\prime}$ at a mole fraction $X_{1}$ of liquid 1 . This parameter quantifies the interactions between water and methanol in the presence of polymer at low concentration:

$$
\begin{aligned}
& \ln \left(\eta_{\mathrm{m}}^{*}\right)-\left[X_{1} \ln \left(\eta_{1}^{*}\right)+\left(1-X_{1}\right) \ln \left(\eta_{2}^{*}\right)\right], \\
& =X_{1}\left(1-X_{1}\right) d_{p}^{\prime}
\end{aligned}
$$

where $\eta_{\mathrm{m}}^{*}, \eta_{1}^{*}$ and $\eta_{2}^{*}$ are respectively the dynamic viscosity of the mixture, liquid 1 and 2 , in the presence of polymer at low concentration.

By combining Equations (2), (3) and (4), the pseudo Grumberg-Nissan constant $d_{p}^{\prime}$ can be connected to the Grumberg-Nissan constant d' as in Equation (5):

$d_{p}^{\prime}-d^{\prime}=\frac{\ln \left(\Gamma_{p}\right)}{X_{1}\left(1-X_{1}\right)}$,

where $\Gamma_{\mathrm{p}}$ is a function depending on the polymer concentration $\mathrm{C}$ and the mole fraction of liquid 1 in the mixture, $X_{1}$; the coefficients $a_{i, j}(1 \leq i \leq 3$ and $\mathrm{j}=1,2, \mathrm{~m})$ are deduced from the viscosity data adjustment as defined in Equations (2) and (3):

$$
\begin{aligned}
\Gamma_{p}\left(X_{1}, C\right)= & \frac{1+a_{1, m} C+a_{2, m} C^{2}+a_{3, m} C^{3}}{\left(1+a_{1,1} C+a_{2,1} C^{2}+a_{3,1} C^{3}\right)^{X_{1}}} \\
& \left(1+a_{1,2} C+a_{2,2} C^{2}+a_{3,2} C^{3}\right)^{1-X_{1}}
\end{aligned}
$$

Finally, the effect of the presence of a polymer on the interaction between unlike molecules in a binary liquid mixture can be expressed by the Grumberg- 
Nissan constant deviation $\delta d_{p}^{\prime}$ given by the following expression:

$\delta d_{p}^{\prime}=d_{p}^{\prime}-d_{p}$

\section{EXPERIMENTAL}

\section{Sample Preparation}

The chemical components, methanol of purum grade and PVP $(\mathrm{M}=360,000 \mathrm{~g} / \mathrm{mol})$ of monodisperse grade, were purchased from Aldrich. Bidistilled water and alcohol were separately filtered through Millipore filters of $0.22 \mu \mathrm{m}$ to eliminate dust. Then, water and methanol mixtures were prepared by weight. To minimize experimental error, the total mass of the prepared mixture, at a given methanol mole fraction $X_{1}$, was taken as $m_{T}=50 \mathrm{~g}$. The concentration, $\mathrm{C}$, of the dissolved polymer was less than the critical concentration for overlapping, $C^{*}$, estimated to be close to $0.6 \mathrm{~g} / \mathrm{dl}$ (Guettari et al., 2010).

\section{Rotational Concentric Cylinder Viscometer}

A Brookfield DV-II + Pro Viscometer of the rotational variety with coaxial cylinder geometry was used. The apparatus measures the torque required to rotate an immersed element, the spindle, in a solution. The spindle is driven by a motor through a calibrated spring. The cylindrical spindle, which we used, is adapted to characterize small samples of low viscosities. For this apparatus the shear rate, $\dot{\varepsilon}$, and shear stress, $\tau$, are given by the following equations (Couarraze and Grossiord, 2000; Steffe, 1996):

$$
\begin{aligned}
& \dot{\varepsilon}=\frac{2 \omega \mathrm{R}_{\mathrm{c}}^{2}}{\left(\mathrm{R}_{\mathrm{c}}^{2}-\mathrm{R}_{\mathrm{b}}^{2}\right)}\left(\mathrm{s}^{-1}\right) \\
& \tau=\frac{\mathrm{M}}{2 \pi \mathrm{R}_{\mathrm{b}}^{2} \mathrm{~L}}\left(\mathrm{dyn} / \mathrm{cm}^{2}\right),
\end{aligned}
$$

where, $R_{c}$ and $R_{b}$ are respectively, the container and spindle radius, $\omega$ is the angular velocity of the spindle ( $\mathrm{rad} / \mathrm{sec}), \mathrm{M}$ is the torque (dyn.cm) and $\mathrm{L}$ is the length of the spindle. For a Newtonian fluid, the shear rate is proportional to shear stress according to the linear equation:

$$
\tau=\eta \dot{\varepsilon}
$$

where $\eta(\mathrm{cP})$ is the dynamic viscosity of the solution. In practice, the dynamic viscosity is the slope of the rheogram: $\tau=\mathrm{f}(\dot{\varepsilon})$. The dynamic viscosities were measured with relative errors less than $3 \%$.

\section{RESULTS AND DISCUSSION}

The shear stress-shear rate rheograms were established for solutions of PVP at $25{ }^{\circ} \mathrm{C}$. All the rheograms obtained showed a linear variation of the shear stress versus the shear rate, as shown by the examples of Figure 1. These rheograms reveal the Newtonian behaviour of the studied solutions and their slopes give us the dynamic viscosities of these solutions.

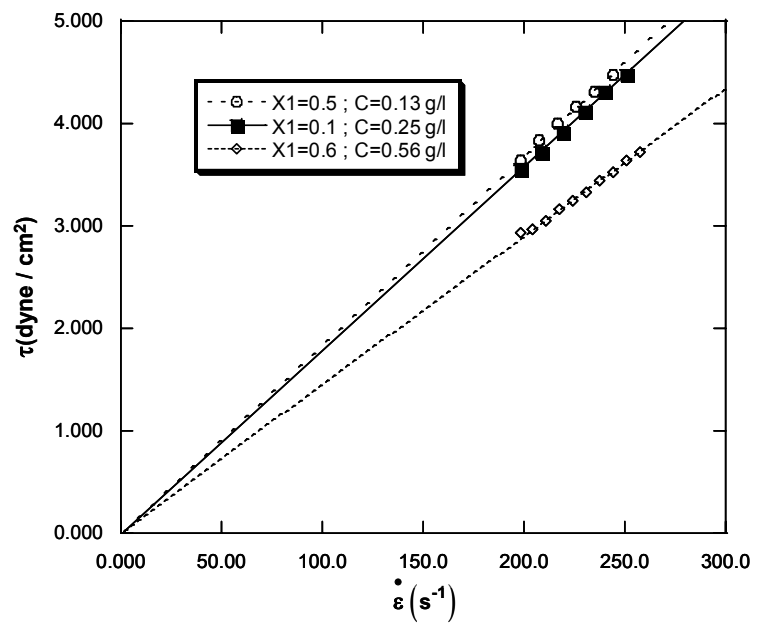

Figure 1: Rheograms of polymer solution for different methanol compositions and polymer concentrations at $25^{\circ} \mathrm{C}$.

We report in Figure 2 the dynamic viscosities of the studied polymer solutions versus the concentration, for different composition of the binary mixture. These curves show a polynomial dependence according to Equation (2). For polymer in pure solvents, the fit of the experimental curves shows that the solution viscosities depend on the polymer concentration at $25^{\circ} \mathrm{C}$ according to the following equations:

In methanol:

$$
\begin{aligned}
\eta_{1}^{*}(C) & =0.541(1+1.227 \mathrm{C} \\
& \left.+3.096 \mathrm{C}^{2}-1.994 \mathrm{C}^{3}+\ldots\right)
\end{aligned}
$$

In water: 


$$
\begin{aligned}
\eta_{2}^{*}(C) & =0.984(1+1.634 C \\
& \left.-1.346 C^{2}+1.375 C^{3}+\ldots\right)
\end{aligned}
$$

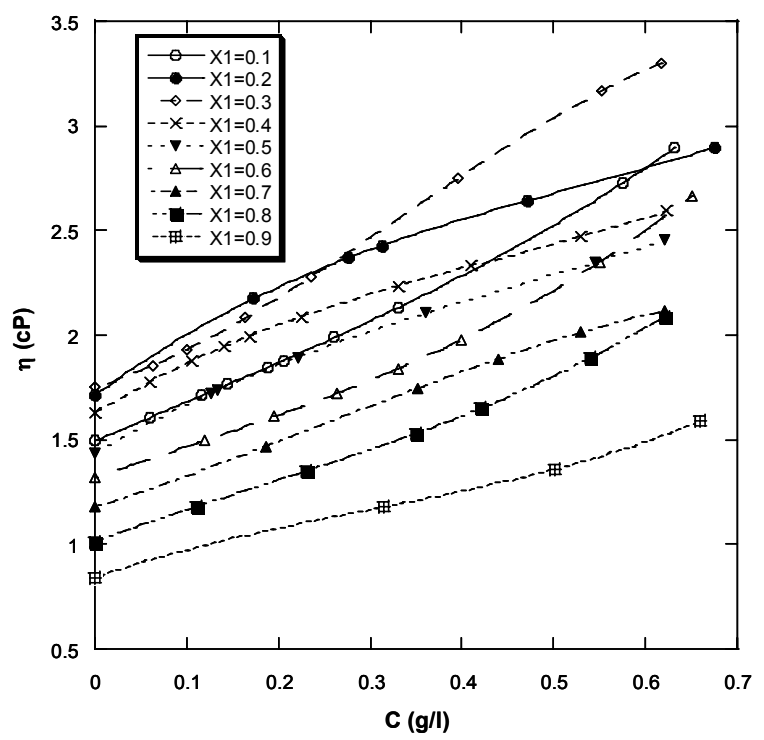

Figure 2: Dynamic viscosity $\eta(\mathrm{cP})$ of polymer solutions vs. polymer concentration for different mixture compositions at $25^{\circ} \mathrm{C}$.

For polymer in mixed solvents, the fit of the experimental curves shows that the solution viscosities follow a polynomial dependence. Table 1 reports the coefficients deduced from the viscosity data adjustment as defined in Equation (3).

Table 1: The fitted dynamic viscosity coefficient $a_{i, m}(i=1-3)$ and the viscosity at zero polymer concentration $\eta_{\mathrm{m}, 0}$ for the polymer solutions at different composition of the mixture

\begin{tabular}{|l|c|c|c|c|}
\hline $\mathbf{X}_{\mathbf{1}}$ & $\eta_{\mathbf{m}, \mathbf{0}}$ & $\mathbf{a}_{\mathbf{1}, \mathbf{m}}$ & $\mathbf{a}_{\mathbf{2}, \mathbf{m}}$ & $\mathbf{a}_{\mathbf{3}, \mathbf{m}}$ \\
\hline 0.1 & 1.495 & 1.253 & -0.157 & 0.821 \\
0.2 & 1.712 & 1.921 & -2.317 & 1.468 \\
0.3 & 1.753 & 0.773 & 2.790 & -2.796 \\
0.4 & 1.629 & 1.652 & -2.114 & 1.583 \\
0.5 & 1.439 & 1.780 & -1.833 & 1.281 \\
0.6 & 1.32 & 1.148 & -0.378 & 1.582 \\
0.7 & 1.178 & 1.182 & 1.062 & -1.445 \\
0.8 & 1.014 & 1.596 & -1.146 & 2.146 \\
0.9 & 0.841 & 1.715 & -2.210 & 2.516 \\
\hline
\end{tabular}

According to Equations (5) and (6), we have calculated the deviation of the Grumberg-Nissan constant, $\delta \mathrm{d}_{\mathrm{p}}^{\prime}$, which is due to the presence of the polymer in the binary liquid, for different compositions $X_{1}$ and polymer concentrations $C$. The variation of the deviation of the Grumberg-Nissan constant versus methanol mole fraction $\mathrm{X}_{1}$ were plotted in
Figures 3 and 4, respectively, for polymer concentrations of $\mathrm{C}=0.1-0.3 \mathrm{~g} / \mathrm{dl}$ and $\mathrm{C}=0.4-0.6 \mathrm{~g} / \mathrm{dl}$. The analysis of the obtained curves show the existence of three different values of the deviation of the Grumberg-Nissan constant, i.e., negative, positive and zero.

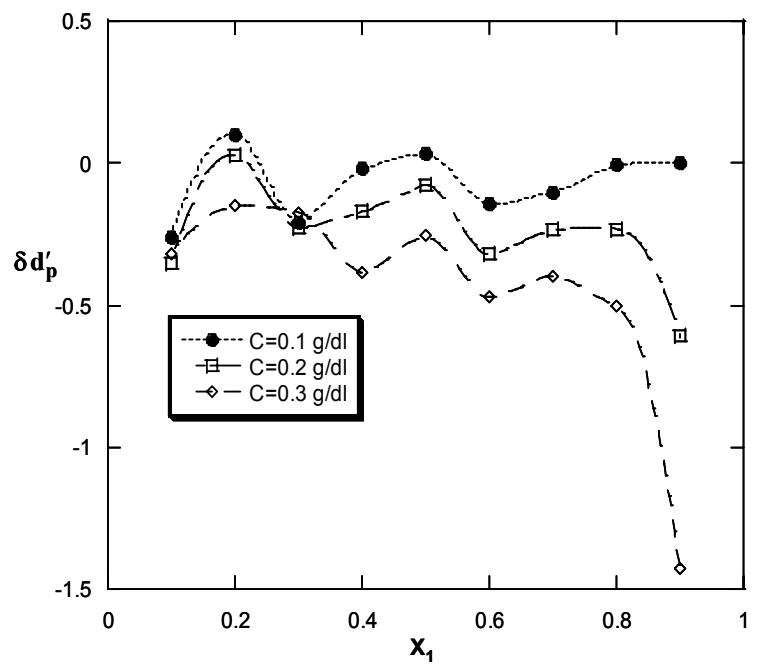

Figure 3: Deviation of the Grumberg-Nissan constant, $\delta \mathrm{d}_{\mathrm{p}}^{\prime}$, vs. methanol molar fraction $\mathrm{X}_{1}$ for the polymer concentration $\mathrm{C}=0.1-0.3 \mathrm{~g} / \mathrm{dl}$.

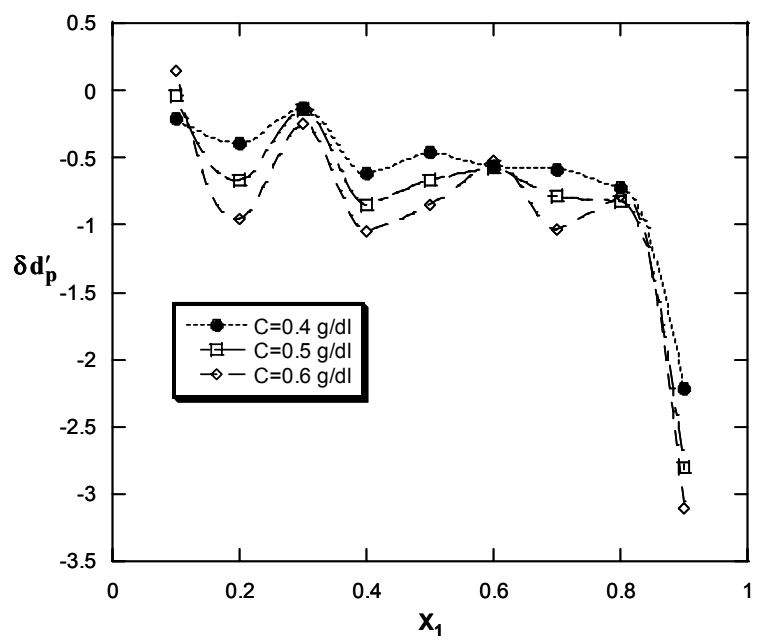

Figure 4: Deviation of the Grumberg-Nissan constant, $\delta \mathrm{d}_{\mathrm{p}}^{\prime}$, vs. methanol mole fraction $\mathrm{X}_{1}$ for the polymer concentrations $\mathrm{C}=0.4-0.6 \mathrm{~g} / \mathrm{dl}$.

Generally, the sign of the deviation of the Grumberg-Nissan constant, $\delta d_{p}^{\prime}$, is negative, which means that the interactions between water and methanol molecules decrease in the presence of polymer. In fact, due to the hydrogen bonds, a complex can be formed between free water and 
methanol molecules according to the following dynamic equilibrium (Zhao et al., 1999):

$$
\text { Water }+ \text { methanol } \leftrightarrow \text { Water-methanol }
$$

The addition of PVP to the binary mixture permits the establishment of hydrogen bonds between polymer and free and/or bonded molecules in the mixture:

Water + PVP $\leftrightarrow$ PVP-water

methanol + PVP $\leftrightarrow$ PVP-methanol

In fact, this type of polymer provides a preferential interaction with one component of the mixture, depending on methanol mole fraction $\mathrm{X}_{1}$ (Guettari and Gharbi, 2011).

Thus, the presence of the polymer induces a perturbation of the dynamic equilibrium between free and complexed molecules at fixed temperature. According to Le Chatelier's principle, the adsorption of a molecule (water or methanol) on PVP should displace the equilibrium between free molecules and the water/methanol complex. This displacement in the complex dissociation induces a reduction of the interaction between unlike molecules and thus a decrease of the Grumberg-Nissan constant, which explains the negative value of the change of the Grumberg-Nissan constant due to the presence of polymer. For the methanol mole fraction of $\mathrm{X}_{1}=0.3$, the deviation of the Grumberg-Nissan constant seems to be independent of the polymer concentration.

However, in a few cases, the deviation of the Grumberg-Nissan constant vanishes. This means that the presence of polymer does not affect the interaction between unlike molecules. This situation was observed especially for the lowest polymer concentration, $\mathrm{C}=0.1 \mathrm{~g} / \mathrm{dl}$ (Fig. 3), which corresponds to very little perturbation of the complex formed between water and methanol due to hydrogen bonds. As the polymer concentration increases, the deviation of the Grumberg-Nissan, $\delta d_{p}^{\prime}$, decreases.

This means that the interactions between unlike molecules decrease upon increasing the number of polymer molecules in the mixture. On the other hand, $\delta \mathrm{d}_{\mathrm{p}}^{\prime}$ decreases spectacularly in the alcohol-rich region, $X_{1}=0.9$, which means that the interactions between water and methanol become much lower and the dissociation of the water/methanol complex is possible.

\section{CONCLUSION}

The quantification of the interaction between unlike molecules is usually described by the Grumberg-Nissan constant. In the presence of a polymer and according to the quasi-binary system hypothesis, the interaction between unlike molecules is quantified by a pseudo Grumberg-Nissan constant. An expression of the deviation of the GrumbergNissan constant due to the presence of a polymer was theoretically established. The application of the established method has determined the effect of the presence of polyvinylpyrrolidone on the mixture of water and methanol at $25^{\circ} \mathrm{C}$.

\section{REFERENCES}

Corsaro, C., Spooren, J., Branca, C., Leone, N., Broccio, M., Kim, C., Chen, S.-H., Eugene Stanley, $\mathrm{H}$. and Mallamace, F., Clustering dynamics in water/methanol mixtures: A nuclear magnetic resonance study at $205 \mathrm{~K}<\mathrm{T}<295 \mathrm{~K}$. J. Phys. Chem., B 112, 10449 (2008).

Couarraze, G., Grossiord, J.-L., Initiation à la Rhéologie. Third Edition, TEC. \& DOC Editions, Paris (2000).

Dixit, S., Soper, A. K., Finney, J. L. and Crain, J., Water structure and solute association in dilute aqueous methanol. Europhys. Lett., 59, 377 (2002).

Dougan, L., Bates, S. P., Hargreaves, R., Fox, J. P., Crain, J., Finney, J. L., Réat, V. and Soper, A. K., Methanol-water solutions: A bi-percolating liquid mixture. J. Chem. Phys., 121, 6456 (2004).

El-Dossoki, F. I., Dissociation and kinetic of hydrochloric acid in mixed isomeric alcoholic-aqueous solvents - A conductance study. J. Mol. Liq., 158, 18 (2010).

Georgiev, G. M., Vasilev, K. and Gyamchev, K., Hydrogen bonds in water-methanol mixture. Bulg. J. Phys., 34, 103 (2007).

Gonzalez-Salgado, D. and Nezbeda, I., Excess properties of aqueous mixtures of methanol: Simulation versus experiment. Fluid Phase Equilib., 240, 161 (2006).

Grunberg, L. and Nissan, A. H., Mixture law for viscosity. Nature 164, 799 (1949).

Guettari, M., Aschi, A., Gomati, R. and Gharbi, A., Structural transition of homopolymer in solvents mixture. Mat. Sci. Eng., C 28, 811 (2008).

Guettari, M., Gomati, R. and Gharbi, A., Effect of temperature on cononsolvency of polyvinylpyrrolidone in water/methanol mixture. J. Macromol. 
Sci. Phys., B 49, 552 (2010).

Guettari, M. and Gharbi, A., A model to study the behavior of a polar polymer in the mixture of polar solvents. J. Macromol. Sci. Phys., B 49, 592 (2010).

Guettari, M. and Gharbi, A., A correspondence between Grunberg-Nissan constant d' and complex varieties in water/methanol mixture. Phys. Chem. Liquids, 49, 459 (2011).

Guo, J., H., Luo, Y., Augustsson, A., Kashtanov, S., Rubensson, J.-El., Shuh, H., Agren, D. K. and Nordgren, J., Molecular structure of alcoholwater mixtures. Phys. Rev. Lett., 91, 157401, 1 (2003).

Haldar, P., Das, B., Viscosities of tetrabutylammonium bromide, sodium tetraphenylborate and sodium bromide in 2-ethoxyethanol + water mixed solvent media at $308.15,313.15,318.15$ and $323.15 \mathrm{~K}$. J. Mol. Liq., 138, 88 (2008).

Huque, M., Siddiquey, I.-A., Nizam Uddin, M., Physico- chemical study of aqueous solutions of electrolytes in mixed solvents. J. Chem. Thermodyn., 38, 1474 (2006).

Laaksonen, A., Kusalik, P. G. and Svishchev, I. M., Three-dimensional structure in water-methanol mixtures. J. Phys. Chem., A 101, 5910 (1997).

Mikhail, S. Z. and Kimel, W. R., Densities and viscosities of methanol-water mixtures. J. Chem. Eng. Data, 64, 533 (1961).

Oleinikova, A., Bulavin, L., Pipich, V., Critical anomaly of shear viscosity in a mixture with an ionic impurity. Chem. Phys. Lett., 278, 121 (1997).

Steffe, J. F., Rheological Methods in Food Process Engineering. 2nd Edition, Freeman Press (1996).

Wakisaka, A., Carime, H. A., Yamamoto, Y. and Kiyozumi, Y., Non-ideality of binary mixtures water-methanol and water-acetonitrile from the viewpoint of clustering structure. J. Chem. Soc. Faraday Trans., 94, 369 (1998).

Wang, P., Anderko, A., Young, R. D., Modeling viscosity of concentrated and mixed-solvent electrolyte systems. Fluid Phase Equilibria, 226, 71 (2004).

Yilmaz, H., Excess properties of alcohol - water systems at 298.15 K Turk. J. Phys. 26, 243 (2002).

Zhao, Z. and Malinowski, E. R., Detection and identification of a methanol-water complex by factor analysis of infrared spectra. Anal. Chem., 71, 602 (1999).

Zhao, Y., Wang, J., Yan, Z., Zhuo, K., Molar volumes and viscosities of $\mathrm{LiClO}_{4}$ and $\mathrm{LiBr}$ in propylene carbonate + 1,2-dimethoxyethane mixed solvents at $298.15 \mathrm{~K}$. Fluid Phase Equilibria, 244, 105 (2006). 